\title{
Effect of Strawberry Density on the Spread of Anthracnose Caused by Colletotrichum acutatum
}

\author{
L. V. Madden and M. A. Boudreau
}

First author: Department of Plant Pathology, The Ohio State University, Wooster 44691-4096; and second author: Department of Biology, Warren Wilson College, Asheville, NC 28815-9000.

Accepted for publication 2 May 1997.

\begin{abstract}
Madden, L. V., and Boudreau, M. A. 1997. Effect of strawberry density on the spread of anthracnose caused by Colletotrichum acutatum. Phytopathology 87:828-838.

Spread of strawberry anthracnose, resulting from the rain splash dispersal of Colletotrichum acutatum conidia, was determined in field plots by assessing fruit disease incidence at a range of distances from an introduced point source of infected fruit with sporulating lesions. Four withinrow plant densities were established in replicated plots in each of 2 years. A generalized linear model with a logit link function and binomial distribution for incidence was used to quantify the effects of distance and side of the row relative to the inoculum source, plant density treatment, and their interactions on disease incidence. At all assessment times, there was a significant $(P \leq 0.05)$ decline in incidence with increasing distance from the spore source. Moreover, row side had a significant effect, with the near side having higher incidence than the far side. Plant density treatment had a significant, but nonlinear, effect on incidence, with incidence

the disease gradient (slope) as well as the overall level of disease incidence, depending on the assessment time and year. The combined effects of plant density and row side on the height and steepness of the disease gradients could be measured using the predicted distance in which incidence equals $10 \%\left(d_{10}\right)$. Estimated $d_{10}$ generally increased in a nonlinear manner with decreasing plant density. Also, plant density had a significant negative effect on the proportion of incident rain that penetrated the canopy. In a separate study, plant density did not consistently affect infection of fruit that had been placed within the canopy immediately after being inoculated in the laboratory with a controlled inoculum density, indicating that conditions favoring infection were similar for the four densities. Thus, differences in mean disease incidence and disease gradients among the treatments were mostly due to differences in dispersal and not to other components of the disease cycle. As previously reported for controlled studies using a rain simulator, however, the effects of plant density on dispersal were complex, and increasing density did not universally lead to decreasing disease incidence.
\end{abstract} generally declining with increasing density. Side of the row relative to the inoculum source and density treatment could affect the steepness of
Additional keywords: Fragaria $\times$ ananassa, quantitative epidemiology.
The role of host density in disease dynamics is poorly understood, but may be important in regulating spatial and temporal aspects of epidemics in both natural and agricultural ecosystems $(6,20)$. In the case of unmanaged or minimally managed communities, a densitydependent plant mortality mediated by pathogen activity has been suggested in some studies $(7,27)$. However, confounding variables in these systems have prevented any demonstration of a clear causal relationship between density and disease $(2,14)$. The situation is more straightforward in agricultural settings, in which a grower exercises control over density directly through planting, replanting, and thinning, and indirectly through pest control, fertility management, etc. This control has allowed empirical evaluations of densitydisease relations and may present an opportunity for new disease management strategies through density regulation for certain crops.

Burdon and Chilvers (6) reviewed studies that included over 40 host-pathogen combinations, the majority of which (62\%) indicated positive correlations between plant density and disease intensity. However, in several pathosystems, a negative correlation, inconsistent results, or lack of relationship between plant density and disease intensity recently have been found $(9,24,27,38)$. Differences in disease cycles, assessment technique, and the occurrence of complicating variables (e.g., changes in host pattern as density changes), make comparison among and generalization from these studies difficult.

Corresponding author: L. V. Madden; E-mail address: madden.1@ osu.edu

Publication no. P-1997-0602-02R

(c) 1997 The American Phytopathological Society
The epidemiological models of Anderson and May (1), which emphasize animal systems, suggest that increasing host density will increase probability of contact of an infectious unit (e.g., spore in transport or spore on a lesion) with a healthy unit (e.g., leaf or fruit) and, therefore, increase rates of development of diseased units. This is, in part, the intuitive basis for speculation that disease will increase with density $(6,39)$, thus, giving pathogen dispersal a primary role in the system. With a few exceptions $(13,34,36)$, there is little empirical evaluation of density effects on pathogen dispersal. A detailed study of the splash-dispersed fungal pathogen Colletotrichum acutatum J.H. Simmonds, cause of strawberry anthracnose, using simulated rain revealed significant reductions in spore deposition (per unit of area and time) within and between strawberry rows with increasing plant density (4). Interestingly, spore deposition did not decrease in a direct linear fashion with increasing plant density, and density still had an effect on deposition between rows when the inoculum source was not within the canopy, but between rows. The authors proposed three mechanisms by which density may influence dispersal: reduction in spore removal from the inoculum source (by sheltering of inoculum), reduction in resplash of spore-carrying droplets, and direct interception of spores in splash droplets by the plant canopy. The results indicated that all three mechanisms were operating and interacting, demonstrating the complicated nature of density influences on dispersal in this system.

The complexity of the splash-dispersal system $(17,28)$ mandates not only a detailed study of individual mechanisms in controlled experiments such as with a rain simulator, but also a phenomenological approach in which the overall impact of density on disease spread in space and time is evaluated for particular crops and path- 
ogens. In this study, we assessed anthracnose fruit rot development from an inoculum point source in strawberry plots planted at a range of densities over each of two seasons. A generalized linear statistical model, which incorporates the spatial and plant density treatment aspects of the epidemic, was utilized for quantifying disease incidence.

\section{MATERIALS AND METHODS}

Plot establishment. Sixteen $2 \times 2$-m plots were planted to strawberry (Fragaria $\times$ ananassa Duchesne 'Midway'; Brittinghams Nursery, Salisbury, MD) in spring 1991 (for the 1992 experiment) and spring 1992 (for the 1993 experiment) on the experimental farm of the Ohio Agricultural Research and Development Center, Wooster, $\mathrm{OH}$. The sites for 1992 and 1993 were separated by $50 \mathrm{~m}$. Plots were $2 \mathrm{~m}$ apart within each site. In both years, three rows, $1 \mathrm{~m}$ apart, were planted in each plot in an east-west orientation and maintained during the first season using routine husbandry techniques including straw mulching and blossom removal (19). The mulch was removed from within the plots (30), but not between plots, during the experiments to help insure adequate intraplot dispersal $(30,43,44)$.

Four plant densities were created, each replicated four times, which unavoidably altered leaf distribution (i.e., patchiness [8]) as well. Plots established in 1991 (for use in 1992) were all planted at $30 \mathrm{~cm}$ between plants (seven plants/row); therefore, density levels required for the 1992 experiments were achieved by a combination of thinning and supplementation with new transplants. The lowest density involved removing every other plant (i.e., the second, fourth, and sixth plants) from each row on 12 May 1992 and removing runners as they rooted throughout the season, maintaining a $60-\mathrm{cm}$ intrarow spacing. The second density was the original 30-cm spacing, and runners were not allowed to establish new crowns. The third density was created by planting a new crown between each extant plant on 8 May and allowing runners to root during the season. The highest density involved adding two new crowns between extant plants on 8 May and a transplanted runner from thinnings in low-density plots on 21 May, taking care not to damage the earlier transplants. Runners were also allowed to establish new crowns in this treatment. The four density treatments resulted in approximately $1.7,3.3,6.7$, and 14.3 plants per meter of row at the beginning of the experiment.

Plots established for the 1993 experiments were initially planted in 1992 at intrarow spacings of $7 \mathrm{~cm}$ (four plots), $15 \mathrm{~cm}$ (four plots), and $30 \mathrm{~cm}$ (eight plots). Four of the low-density plots were thinned to 60-cm spacing in May 1993 to achieve the fourth density. Again, runners were only allowed to root in the two highdensity plots. Plants per meter of row were the same as in 1992.

Inoculation and assessment. Plots were infested by placing five infected fruit with abundant conidia, prepared as previously described $(31,44)$, midway between the south and middle rows at the east end of each plot. This is similar to that done by Madden et al. (Fig. 1 in literature citation 30), except that they placed their inoculum $30 \mathrm{~cm}$ from the end of the rows. Inoculum placement was done when susceptible (white-colored) fruit were abundant, and immediately prior to a rain event. This occurred on 14 June 1992 and 7 June 1993. Ripe fruit were removed by hand from all plants prior to infestation. The inoculum source fruit were removed after $24 \mathrm{~h}$.

Plots were assessed approximately twice weekly by removing ripe fruit from the plots and recording disease status (diseased/ healthy [symptomless]) and position (distance from east end of row, row number, and side of row). Fruit on the easternmost plant of the south and middle rows were not removed from the plots to provide a continuing inoculum source through the experiment. Removing fruit throughout the rest of the plots mimicked standard commercial harvesting techniques, and also reduced secondary disease spread, since inoculum was removed with the diseased fruit. Assessments for the 1992 experiments took place on 23, 26, and
29 June, and 2 July. In 1993, assessments occurred on 17, 21, 24, and 29 June.

All assessed fruit were assigned to distance categories based on calculated straight-line distances from the original inoculum source, as done previously (30). Fruit disease incidence was determined as the proportion of fruit with anthracnose symptoms $(y)$ for each row side (near or far side, relative to the inoculum) in each of several distance categories. The categories were 0 to 60,61 to 120,121 to 180,181 to 240 , and $241+\mathrm{cm}$; the midpoints of these distances were used as the actual distance in graphs and analyses. Categories were used to obtain a sufficient number of fruit to calculate $y$ as a function of distance from the source.

Rain collection. Rain near ground level within a row (throughfall plus leafdrip) was measured to assess the influence of plant density treatment on rain penetration of the canopy. The method collected rain that was not directly intercepted by the canopy and also intercepted rain that subsequently dripped or splashed to the ground. It did not collect rain that was intercepted and then evaporated, absorbed, or splashed away from the row. Polypropylene disposable cups (89-ml volume, opening diameter of $5.3 \mathrm{~cm}$; Solo Cup Co., Urbana, IL) were used to collect rain approximately 1 to $2 \mathrm{~cm}$ above the soil surface. To allow easy removal of the cups and prevent soil and surface water from entering them, a rubber stopper was taped to the bottom of the cup, and the assembly placed in a second cup permanently buried in the ground, with holes punched in the bottom for drainage. In 1992, rain was collected at two locations in one row of each replicate plot, using the central $1 \mathrm{~m}$ of the row most interior to the area containing all plots. One sample cup was placed midway between nonrunner crowns, and a second near to a nonrunner crown. Four additional cups were located in open areas of the research site with no canopy. Fourteen rain episodes were sampled, which included times before inoculum was introduced and after the disease assessments were finished.

In 1993, two samples were again taken in each plot and four in open areas, but positioning was slightly different to accommodate testing of raindrop sampling units, described elsewhere (3). A sampling cup was placed approximately $50 \mathrm{~cm}$ from either end of the middle row of each plot, each cup positioned one-quarter of the distance between adjacent nonrunner crowns. That is, each cup was located halfway between one nonrunner crown and the point midway between this crown and an adjacent nonrunner crown. Ten rain episodes were sampled. In both years, water volume in each cup was recorded as soon as possible after a rain event, usually within 1 to $2 \mathrm{~h}$.

Total rainfall (cubic centimeters per square centimeter, converted to a depth measurement of millimeters) within and outside the canopy for each rain event was calculated from the water volume collected in each rain sample cup, the area of the cup, and the duration of the event determined from a tipping-bucket rain gauge (model TE525; Campbell Scientific Inc., Logan, UT) located adjacent to the plots. Data from the two cup locations in a plot were averaged for a whole-plot estimate, except for the lowest density plots. In this case, sample cups midway between plants always occurred in open gaps in the canopy. It was estimated that such gaps covered one-third of the row area sampled, whereas two-thirds of the row was under canopy and sampled by the second cup nearer the crown. Data from the two cups were weighted accordingly to reflect the areas sampled to obtain a whole-plot rainfall estimate. Data for each plot was divided by the mean value from the sample cups outside the plots to determine rainfall amount relative to ambient amount.

In addition to the rain measurements, a sheltered thermistor and a leaf wetness grid (models 107 and 237, respectively; Campbell Scientific Inc.) were used to electronically measure temperature and leaf wetness at mid-canopy level in one row of one plot representing each treatment. Similar probes and a resistance-based relative humidity sensor were positioned at the site away from the strawberry canopy. Data were recorded at 10-min intervals throughout 
the season on a $21 \mathrm{X}$ datalogger (Campbell Scientific Inc.). An 'index of predicted infection' associated with each rain event was calculated based on the wetness duration (rain duration plus wetness period after the rain stopped) and average temperature during the wet period. The index was calculated using equation 3 in Wilson et al. (41), as done previously (30), and was based on the predicted proportion of inoculated fruit that became infected by $C$. acutatum in controlled studies with the specified wetness duration and temperature.

Infection, postdeposition. A study was done to determine if the micro-environment within the canopies varied with respect to favorableness for fruit infection. The effect of plant density treatment on infection of fruit, postdeposition, was assessed by determining disease incidence of inoculated, detached fruit placed within each treatment row canopy and in unsheltered areas adjacent to the plot site. Greenhouse-grown fruit ('Midway') at the white stage were collected with the pedicels and inoculated in the laboratory as previously described (43), but with $1 \times 10^{3}$ conidia/ml. This inoculum density produces a fruit disease incidence of approximately 0.5 with $12 \mathrm{~h}$ of wetness and $25^{\circ} \mathrm{C}$ in controlled-environment chambers (41).

The inoculated fruit were brought immediately to the field and pedicels placed in small holders made of $200-\mu l$ polystyrene pipette tips (Oxford Labware, St. Louis), the ends of which had been sealed by melting. The holders were inserted in the ground and filled with distilled water, so that the fruit pedicel could be submerged to prevent drying, but the fruit itself rested above the holder lip and was exposed to the environment. All holders were cleaned with $95 \%$ ethanol 1 to 2 days earlier and rinsed three times before being filled with the water. Six holders were placed randomly within each row of the two highest densities. For the lowest two densities, three holders were randomly placed in the part of the rows farthest from the crowns ("gaps"), and three holders were placed in the part of the rows located near the crowns ("patches"). To observe infection where no canopy was present, four replicate "plots" with three "rows" each were identified in the rototilled area around the strawberry plots, and the holders were placed here as well. Inoculated fruit were placed in holders in the early evening before dew formed, and later removed to labeled jars for assessment in the laboratory. The experiment was conducted three times, 21 to 27 July, 6 to 13 August, and 17 to 26 August 1992. All 18 fruit holders were used in each plot of each treatment in the first repetition of the experiment, but, because of low fruit production in the greenhouse, only nine holders were used in each plot in the last two repetitions.

Data analysis. The effects of plant density treatment $\left(T_{i} ; i=1\right.$ [highest density], 2, 3, or 4 [lowest density]), row side $\left(S_{j} ; j=1\right.$ [near] or 2 [far]), distance from the inoculum source $(d$; a continu-

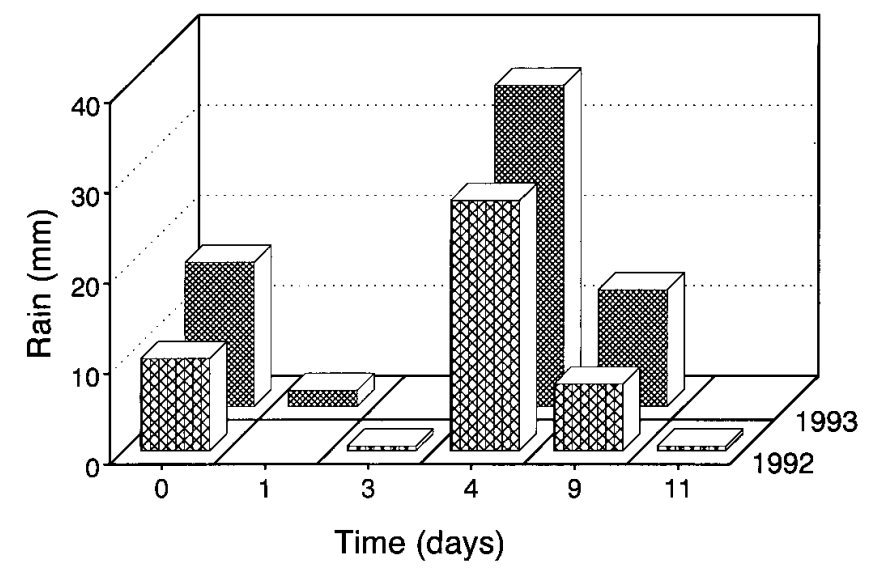

Fig. 1. Amount of rain collected $(\mathrm{mm})$ in a rain gauge adjacent to the strawberry plots in 1992 and 1993. Time is days from introduction of inoculum into the plots. ous variable), and their interactions on fruit disease incidence ( $y ; 0$ to 1) were determined with a generalized linear model (GLM) $(11,23)$ using the program GLIM $(12,22)$. Treatment and row side were considered category (or class or factor) variables, with four and two levels, respectively, instead of continuous variables. Because increasing plant density unavoidably changed more than just the leaf area or number of leaves (or fruit) per unit area of crop row, considering treatment as simply a continuous variable was considered inappropriate. The logit link function for $y$ was used as the response variable, and binomial distribution for $y$ was assumed (23).

With the GLM, for a selected row side and treatment, the disease gradient can be written as

$$
\ln [p /(1-p)]=a^{\prime}-b^{\prime} d
$$

in which $p$ is the probability of a fruit being diseased, estimated with $y$, and $\ln [p /(1-p)]$ is the logit link. Equation 1 is the extension of the exponential dispersal model when dealing with proportions $(8,25) ; b^{\prime}$ is the slope (units of reciprocal centimeters), a measure of gradient steepness; and $a^{\prime}$ is predicted $\ln [p /(1-p)]$ at $d$ $=0$. That is, $a^{\prime}=\ln \left[p_{0} /\left(1-p_{0}\right)\right]$, with $p_{0}$ being the probability of a fruit being diseased at $d=0\left(p_{0}=1 /\left[1+\exp \left(-a^{\prime}\right)\right]\right)$. Because $d=0$ is not a measurable distance in this study (i.e., the smallest $d$ with fruit is $30 \mathrm{~cm}$ [midpoint of the 0 - to 60 -cm distance category]), $a^{\prime}$ is interpreted more simply as the height of the equation 1 line near the inoculum source, or overall magnitude of disease incidence. If $b^{\prime}$ varies among groups (e.g., treatments), interpretation of $a^{\prime}$ is more complicated, because lines are not parallel and overall line height is not a useful concept. Based on estimated $a^{\prime}$ and $b^{\prime}$, the predicted distance at which a specific incidence is reached can be determined. For instance, $d_{10}$, the predicted distance in which $p=$ 0.10 , is given by $\left[a^{\prime}-\ln (0.10 / 0.90)\right] / b^{\prime}=\left(a^{\prime}+2.2\right) / b^{\prime}$.

The full GLM can be written as

$$
\ln [p /(1-p)]=a-b d+T_{i}+(b T)_{i} d+S_{j}+T S_{i j}+(b S)_{j} d+(b T S)_{i j} d
$$

in which $a$ is a constant (mean); $b$ is the slope of the disease gradient if no other terms are significant; $T S_{i j}$ is the interaction of plant density treatment and row side for overall incidence; and $(b T)_{i} d,(b S)_{j} d$, and $(b T S)_{i j} d$ are the interactions of $T_{i}, S_{j}$, and $T S_{i j}$ with $d$. This is analogous to an analysis of covariance with normal error statistical theory (11). As an example of a reduced form of this model, if only $a, d$, and $S_{j}$ were significant (i.e., all other terms in equation 2 are 0 ), then height of the gradient line (equation 1) for each row side is given by $a^{\prime}=a+S_{j}$ (i.e., $a+S_{1}$ for the near side and $a+S_{2}$ for the far side), and there is a single slope, $b^{\prime}=b$. Because there are only two levels for $S_{j}$ (near $[j=1]$ or far $[j=2]$ row side), the factor reduces to a single implicit binary variable multiplied by a parameter (e.g., $S_{j}=c X$ ). Here, $c$ is an unknown parameter (to be estimated), $X=0$ for the near $(j=1)$ row side, and $X=1$ for the far $(j=2)$ side. For the near side, $S_{1}=$ $c X=c \cdot 0=0$; for the far side, $S_{2}=c X=c \cdot 1=c$. If $a, d, S_{j}$, and $(b S)_{j} d$ are significant, then equation 2 becomes

$$
\begin{aligned}
\ln [p /(1-p)] & =a-b d+S_{j}+(b S)_{j} d \\
& =\left(a+S_{j}\right)-\left[b-(b S)_{j}\right] d
\end{aligned}
$$

which is a line (equation 1) with height $\left(a^{\prime}=a+S_{j}\right)$ and slope $\left(b^{\prime}\right.$ $=b-[b S]_{j}$ ) dependent on row side (i.e., the adjustment to the overall slope $\left[\{b S\}_{j}\right]$ takes on values of 0 [for the near row side] and a nonzero coefficient for the far side $\left.\left[\{b S\}_{2}\right]\right)$. Because treatment has four levels, the factor $T_{i}$ represents three implicit variables, each consisting of zeros and ones (11), multiplied by coefficients, and the value of $T_{i}$ depends on the summation of the coefficients multiplied by the implicit binary variables. Standard terminology with GLMs involves using symbols such as $T_{i}$ for the pooled implicit variables (11).

Maximum likelihood was used for parameter estimation, and significance of all terms in the model were determined by an analysis of deviance (11). Specifically, a chi-square test was used to determine the significance of the change in deviance as each term 
was added (or removed) from the model. Because the $T_{i}$ term represents four levels of plant density, its deviance was partitioned into linear and nonlinear (= quadratic + cubic) orthogonal components (11). Here, "nonlinear" is referring to the density variable, not the parameters; by definition, equation 2 is linear in the parameters. A separate GLM was fitted to the data from each disease assessment and year.

The relationship between disease incidence per plot (totaled over all distances and row sides) and number of fruit per plot $(N)$ was further assessed for disease gradient studies of 1992 and 1993 using a separate GLM. The model can be written as

$$
\ln [p /(1-p)]=\alpha+\beta / N
$$

in which $\alpha$ and $\beta$ are parameters estimated with maximum likelihood, assuming a binomial distribution for incidence. Moreover, the relationship between total number of diseased fruit per plot and $N$ was assessed using the following GLM:

$$
\ln (\mu)=\alpha+\beta / N
$$

in which $\mu$ is the expected number of diseased fruit, obtained from the actual number of diseased fruit, and $\ln (\mu)$ is the log link function for the GLM. A Poisson distribution was assumed for diseased fruit per plot. For the analyses with equations 3 and 4, no direct consideration is made of treatment density, although $N$ is obviously related to treatment, since number of fruit per plot is dependent on plants per plot.

The effects of density treatment $\left(T_{i}\right)$ and rain episode time $\left(E_{k} ; k\right.$ $=1, \ldots)$ on the proportion of incident rain penetrating the canopy ( $r$ ) was determined with repeated measures analysis of variance (ANOVA) (32), with $E_{k}$ serving as the repeated measure. The response variable $(r)$ was log-transformed prior to ANOVA to stabilize variances. A separate analysis was done for each year.

Effects of plant density treatment on disease incidence of fruit inoculated in the laboratory and placed within the canopies was determined with a GLM (11). Logit link function was used and the binomial distribution was assumed. Statistical methods for determining significance were the same as for disease spread (equation 2).

\section{RESULTS}

Incident rain and summary of environmental conditions. There was $10 \mathrm{~mm}$ of rain for the rain episode that immediately followed placement of the infected source fruit in the field plots for the 1992 disease gradient study (Fig. 1). There were four more rain events up to 26 June. The 'index of predicted infection' (30, 41) for the first rain was 0.15 . Average temperatures within the
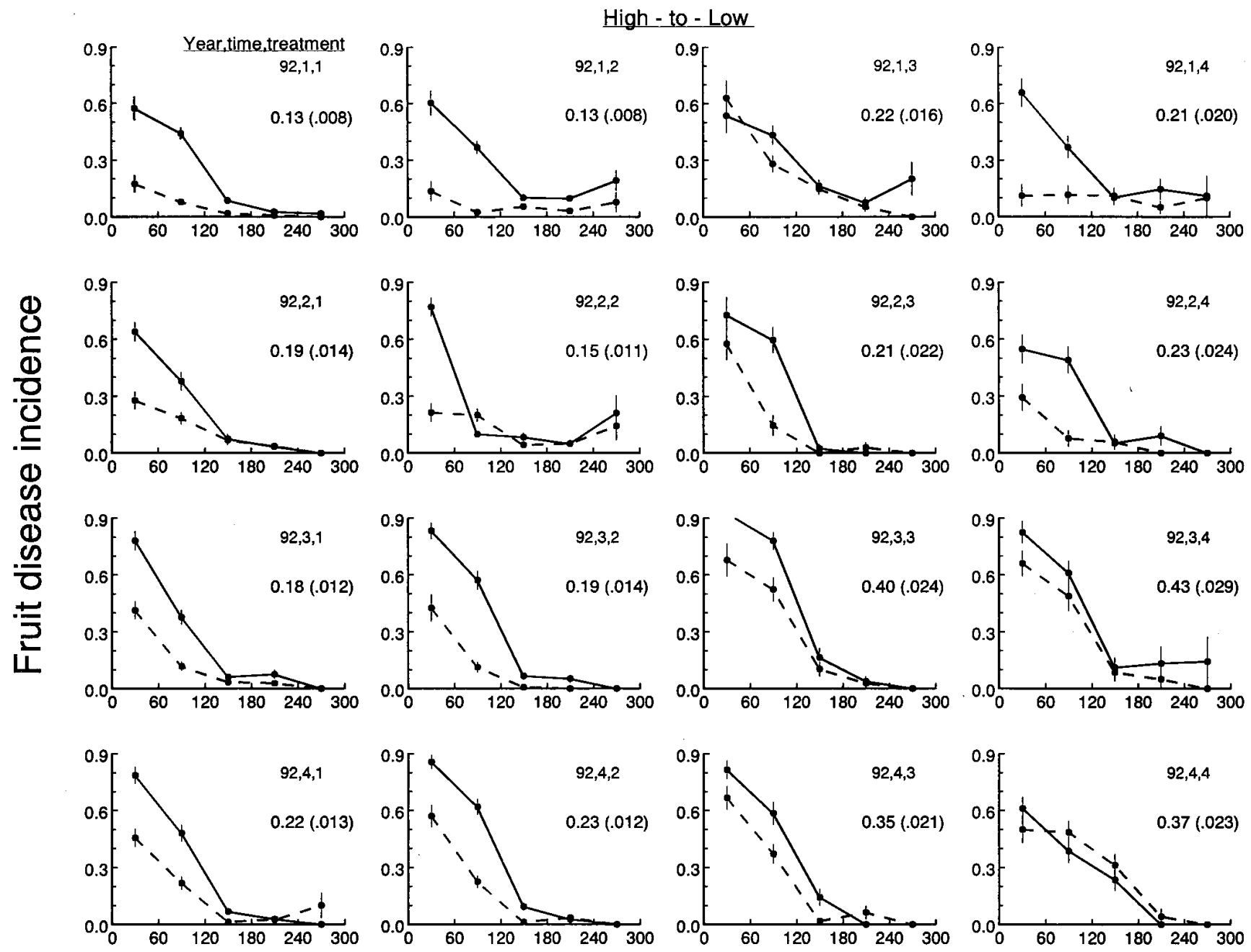

\section{Distance $(\mathrm{cm})$}

Fig. 2. Mean proportion of fruit visibly infected by Colletotrichum acutatum ( \pm standard errors) in relation to distance from point source of infected fruit in strawberry plots of four different plant densities (1 [high] to 4 [low], left to right across figure) at each of four assessment times (top to bottom of figure) in 1992. Lines within each subplot are for the near (solid) and far (dashed) side of rows relative to the initial inoculum source. Insert numbers are the treatment means (standard errors in parentheses) across all distances and row sides. For treatment 3 at the third time and near row side, mean disease incidence is 0.93 (cut off because of the common scale for all plots). 

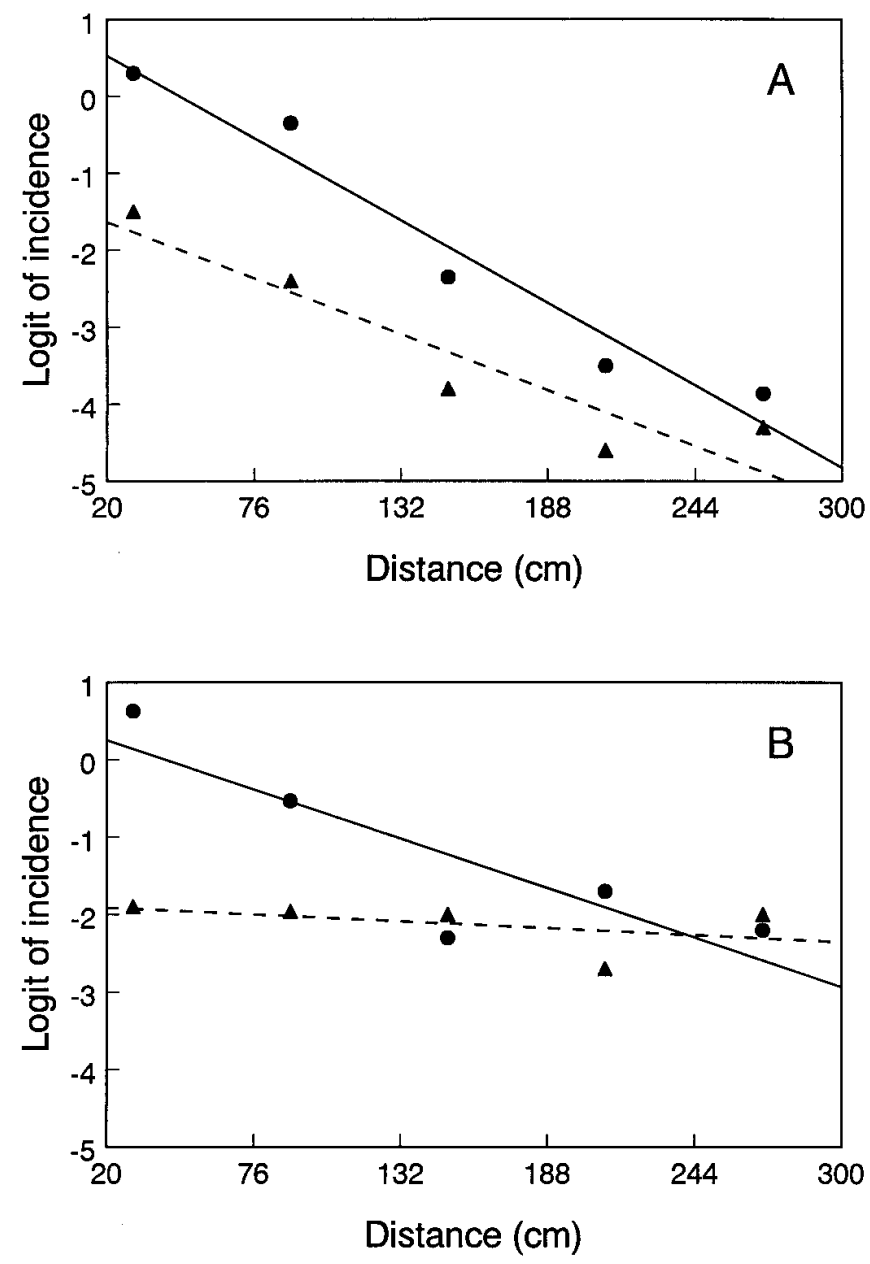

Fig. 3. Examples of logit transformation of the proportion of strawberry fruit visibly infected by Colletotrichum acutatum in relation to distance from the inoculum point source and predicted logit based on equation 1. A, Treatment 1 at the first disease assessment time; and $\mathbf{B}$, treatment 4 at the first assessment time, both in 1992. Solid line is for the near side and dashed line is for the far side of the plant rows, relative to the initial inoculum source. four treatment canopies for the $24 \mathrm{~h}$ after introduction of inoculum were $19.0,19.0,18.8$, and $19.2^{\circ} \mathrm{C}$ for treatments 1 through 4 , respectively. For the entire period from introduction of inoculum to last assessment, mean temperatures were $18.5,19.5,18.1$, and $18.6^{\circ} \mathrm{C}$ for treatments 1 through 4 , respectively. Mean temperature outside the canopies was $19.7^{\circ} \mathrm{C}$. The mean numbers of hours per day of surface wetness were 8.1 to 8.5 for the four treatments and outside the row area.

In 1993, there was $16 \mathrm{~mm}$ of rain immediately following the placement of inoculum in the field. There were three more rains by 26 June (Fig. 1), and the 'index of predicted infection' was 0.90 for the first rain. Average temperatures for the $24 \mathrm{~h}$ after introduction of inoculum and for the entire period were, respectively, 17.6 and $21.2^{\circ} \mathrm{C}, 17.7$ and $21.2^{\circ} \mathrm{C}, 17.8$ and $21.6^{\circ} \mathrm{C}, 19.1$ and $23.0^{\circ} \mathrm{C}$, and 19.3 and $23.2^{\circ} \mathrm{C}$ for treatments 1 through 4 and the clear area outside the plots, respectively. Mean surface wetness duration per day was $5.0,6.1,6.1,4.8$, and $6.7 \mathrm{~h}$ for treatments 1 through 4 and the clear area, respectively.

Disease gradients, 1992. For the first disease assessment, 9 days after introducing infected fruit into the plots, mean fruit disease incidence (for all distances and row sides) ranged from 0.13 in treatment 1 (high plant density) to 0.21 in treatment 4 (low density) (stated in text inserts in top row of subplots in Fig. 2). For subsequent assessments, mean disease incidence was between 0.15 and 0.43 (Fig. 2). Incidence was from 1.7 to 2.4 times higher in the lower two density treatments compared with the higher two density treatments. As expected, there was a decline in mean incidence with distance from the inoculum source (Fig. 2). For the distances close to the inoculum source, incidence on the far side of plant rows (relative to the source) was less than for the near side of the rows for most density treatments and assessment times.

Equation 1 generally provided a good fit to fruit disease incidence in relation to distance. Examples for the near and far row sides of the high (treatment 1) and low (treatment 4) densities of the first assessment are shown in Figure 3. The full GLM (equation 2) explained from 82 to $96 \%$ of the deviance (i.e., variation) over all assessment times (Table 1). The main effects of $d, S_{j}$, and their interaction were all significant $(P \leq 0.05)$, confirming that disease incidence declined with distance, depended on row side (Fig. 2), and that the steepness of the disease gradient (slope of equation $1\left[b^{\prime}=b-\{b S\}_{j}\right]$ ) depended on row side (Figs. 2 and 3).

TABLE 1. Analysis of deviance ${ }^{a}$ for the effects of distance from the inoculum, row side relative to the inoculum source, plant density treatment, and their interactions on proportion of fruit infected by Colletotrichum acutatum for four disease assessments in each of 2 years

\begin{tabular}{|c|c|c|c|c|c|c|c|c|c|}
\hline \multirow[b]{2}{*}{ Factor } & \multirow[b]{2}{*}{$\mathrm{df}^{\mathrm{b}}$} & \multicolumn{4}{|c|}{1992 assessment } & \multicolumn{4}{|c|}{1993 assessment } \\
\hline & & 1 & 2 & 3 & 4 & 1 & 2 & 3 & 4 \\
\hline Distance $(d)$ & 1 & $386.5 * * c$ & $406.9 * *$ & $798.7 * *$ & $968.8^{* *}$ & $143.6^{* *}$ & $82.0 * *$ & $49.9 * *$ & $53.9 * *$ \\
\hline Treatment $(T)$ & 3 & $39.8 * *$ & $20.4 * *$ & 103.** & $20.4 * *$ & $17.2 * *$ & $11.4 * *$ & 7.6 & $17.7 * *$ \\
\hline Linear & $(1)^{\mathrm{d}}$ & $(19.2 * *)$ & $(0.6)$ & $(77.0 * *)$ & $(17.5 * *)$ & $(10.5 * *)$ & $(0.4)$ & $\ldots$ & $(13.1 * *)$ \\
\hline Nonlinear & (2) & $(20.6 * *)$ & $(19.8 * *)$ & $(26.1 * *)$ & (2.9) & $(6.7 *)$ & $(11.0 * *)$ & & $(4.6)$ \\
\hline Nonlinear $\times d$ & (2) & $(22.9 * *)$ & $(22.0 * *)$ & $\left(7.5^{*}\right)$ & $\left(18.9^{* *}\right)$ & $\ldots$ & $\ldots$ & $\ldots$ & $(4.8)$ \\
\hline$T \times S$ & 3 & $38.4 * *$ & $13.8 * *$ & $17.5^{* *}$ & $36.2 * *$ & $13.1 * *$ & 6.9 & $11.1^{*}$ & 0.5 \\
\hline Linear $\times S$ & (1) & $(18.5 * *)$ & (2.5) & $(17.4 * *)$ & $(35.8 * *)$ & $(0.5)$ & $\ldots$ & (2.0) & $\ldots$ \\
\hline Nonlinear $\times S$ & (2) & $(19.9 * *)$ & $(11.3 * *)$ & $(0.1)$ & $(0.4)$ & $(12.6 * *)$ & $\ldots$ & $(9.1 *)$ & \\
\hline$T \times d \times S$ & 3 & $10.9^{*}$ & 4.9 & 3.4 & 0.9 & 2.0 & 6.5 & $11.2 *$ & 1.0 \\
\hline Linear $\times d \times S$ & (1) & $(0.0)$ & $\ldots{ }^{e}$ & $\ldots$ & $\ldots$ & $\ldots$ & $\ldots$ & $(1.0)$ & $\ldots$ \\
\hline Nonlinear $\times d \times S$ & (2) & $(10.9 * *)$ & $\ldots$ & $\ldots$ & & $\ldots$ & $\ldots$ & $\left(10.2^{* *}\right)$ & $\ldots$ \\
\hline
\end{tabular}

${ }^{a}$ Generalized linear model with binomial error and logistic link function (equation 2 in text). For simplicity here, subscripts are not given on the symbols (e.g., $S$ instead of $\left.S_{j}\right)$, and $(b T)_{i} d,(b S)_{j} d$, and $(b T S)_{i j} d$ are given as $T \times d, S \times d$, and $T \times d \times S$, respectively.

${ }^{\mathrm{b}}$ Degrees of freedom.

${ }^{\mathrm{c}}$ Change in deviance from adding the listed factor (or interaction) term to the model containing previously listed factors (or in teractions). For the first line, the previous model would be one with only the mean (constant). Values followed by * or ** are significant at $P=0.05$ and $P=0.01$, respectively.

d Values for df or deviance in parentheses correspond to a partitioning of the treatment deviance into linear and nonlinear components.

${ }^{\mathrm{e}}$ Linear and nonlinear component not determined because the factor or interaction was not significant $(P>0.05)$. 
$T_{i}$ also was significant $(P \leq 0.01)$ at each time, demonstrating that plant density treatment affected disease incidence (Table 1). Partitioning the $T_{i}$ deviance into orthogonal components showed that there was a nonlinear change in disease incidence $(P \leq 0.01)$ with plant density in three of four assessment times (Table 1). This nonlinear effect can be seen by the low and approximately equal mean $y$ (across all distances and row sides) for the higher two densities (e.g., $y \approx 0.19$ for the third assessment) (Fig. 2) and high and approximately equal mean $y$ for the lower two densities (e.g., $y \approx$ 0.41 for the third assessment).

Plant density treatment also affected the steepness of the disease gradients, as indicated by the significant interaction of $T_{i}$ and $d$ (i.e., $[b T]_{i} d ; P \leq 0.05$ ) (Table 1 ). However, the effect was nonlinear (Table 1). An example of this can be seen in Figure 3, where the slopes in 3A (treatment 1) and 3B (treatment 4) are different for the same row side. $S_{j}$ and $T_{i}$ also interacted, showing the influence of row side was not the same for all plant density treatments. For instance, at the first assessment time, the near row side had a higher $y$ than the far row side, except for the third treatment, in which the two sides had virtually identical incidence (Fig. 2). Moreover, for the first assessment time only, there was a significant three-way interaction (Table 1).

Estimates of the intercept $\left(a^{\prime}\right)$ and slope $\left(b^{\prime}\right)$ of equation 1 at each time for all combinations of $T_{i}$ and $S_{j}$ are given in Table 2. These estimates are based on the significant terms of equation 2 (Table 1) and not individual regressions. Because of the various two- and three-way interactions, $a^{\prime}$ and $b^{\prime}$ are different for each combination of treatment and row side. By definition, different values of $a^{\prime}$ and $b^{\prime}$ shown in Table 2 are significantly $(P \leq 0.05)$ different. Except for the third density treatment $\left(T_{3}\right)$, at some times, $a^{\prime}$ (and hence $p_{0}$ ) was higher for the near side (relative to the inoculum source) than the far side of the plant rows (e.g., 1.7 $\left[p_{0} \approx 0.8\right]$ versus $-0.9\left[p_{0} \approx 0.3\right]$ for treatment 1 at assessment 1$)$. Likewise, $b^{\prime}$ was larger on the near than far row sides.

Despite the higher mean disease incidence at the lower two plant density treatments compared with the higher two (text inserts in subplots in Fig. 2), $a^{\prime}$ values generally were low for the lower plant densities (Table 2). However, $b^{\prime}$ values also were low- er (i.e., closer to 0), resulting in overall higher disease incidence for the lower two densities. Using estimates of $a^{\prime}$ and $b^{\prime}, d_{10}$ was calculated and found to be strongly affected by treatment and row side (Table 2). In general, $d_{10}$ was almost always higher for the near than far row sides; for instance, in the highest plant density at the first assessment, $d_{10}$ was 159 and $69 \mathrm{~cm}$ for the near and far row sides, respectively. At the first time, $d_{10}$ for the near side was from 1.2 to 2.3 times larger than for the far side. There was a general increase in $d_{10}$ with decreasing plant row density. For example, $d_{10}$ was 152 and $186 \mathrm{~cm}$ for the near row sides of treatment 1 (high density) and treatment 4 (low density), respectively, at the fourth assessment time.

Disease gradients, 1993. Ten days after introducing infected fruit into the strawberry plots, average fruit disease incidence (across all distances and row sides) ranged from 0.08 in treatment 1 to 0.18 in treatment 3 (text inserts in top row of subplots in Fig. 4). For the latter three assessments, mean incidence ranged from 0.01 to 0.13 . Overall, disease incidence was less in 1993 than in 1992 (Fig. 2). There was a general decline in disease incidence with increasing distance from the source at all assessment times, and incidence for the near side of rows (relative to the inoculum source) was often greater than for the far side of rows at distances close to the source. For the first and last assessments, there was a tendency for disease incidence to be lower in the high density plots (treatment 1) compared with the lower density plots; the highest incidence was found for an intermediate plant density treatment (treatment 3) (Fig. 4). For the second and third assessments, disease incidence was very low (mean $y \leq 0.05$ ) for all treatments, and density treatment effects were not obvious by simple inspection of the means.

The full GLM (equation 2) explained 71 to $86 \%$ of the deviance over the four assessment times (Table 1). The main effects of $d$ and $S_{j}$ were significant $(P \leq 0.01)$ at all times. However, the interaction of these two factors was not significant $(P>0.10)$, indicating that the steepness of disease gradients (i.e., slope $\left[b^{\prime}\right]$ of equation 1) did not depend on the row side. $T_{i}$ was significant $(P \leq 0.01)$ for three of four assessment times, but the linear component was only significant at the first and last times, in which there was an obvious-

TABLE 2. Estimated parameters of the generalized linear model ${ }^{\mathrm{a}}$ fitted to the proportion of fruit infected by Colletotrichum acutatum for four disease assessments in each of 2 years

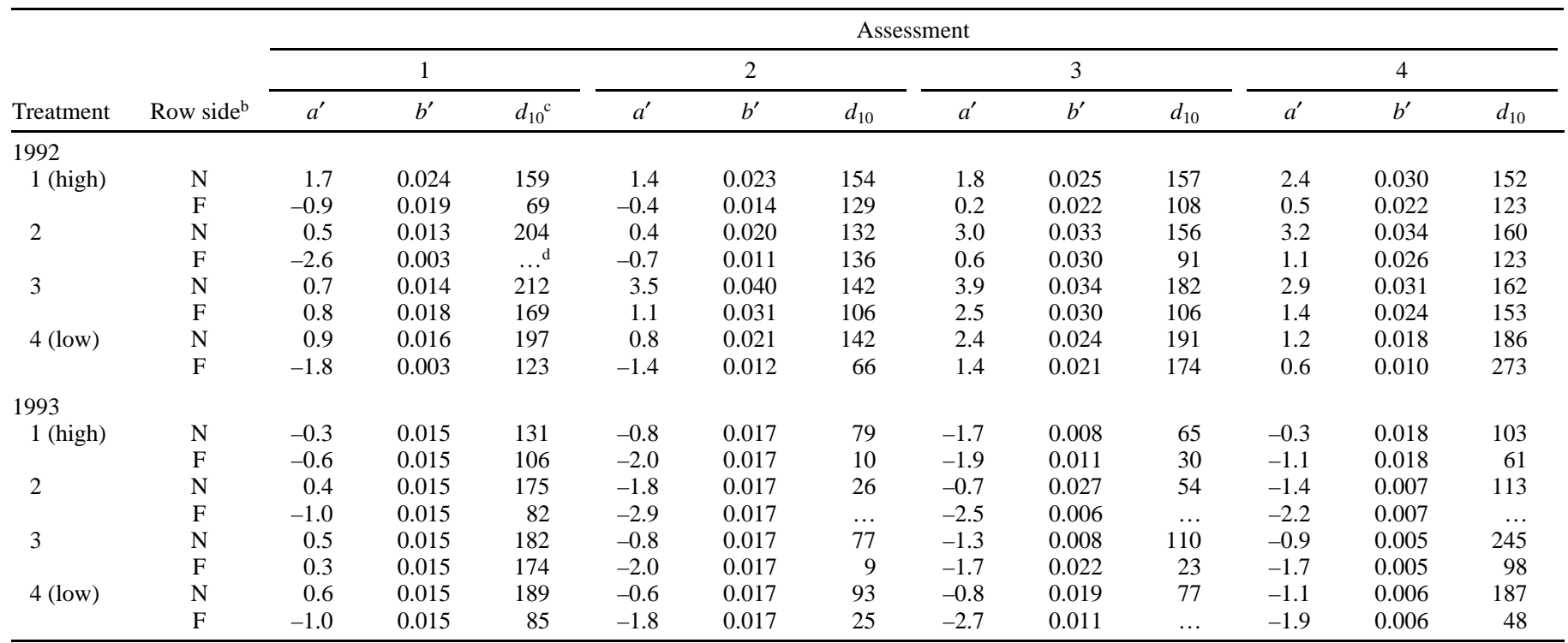

a Model: $\ln [p /(1-p)]=a^{\prime}-b^{\prime} d$, in which $p$ is the probability of a fruit being infected (estimated by proportion diseased), $d$ is distance (cm), $a^{\prime}$ is a parameter for height of the line (predicted logit at $d=0$ ), and $b^{\prime}$ is a parameter for steepness of the gradient $\left(\mathrm{cm}^{-1}\right)$. Estimates of $a^{\prime}$ and $b^{\prime}$ are based on the significant main effects and interactions (Table 1).

${ }^{\mathrm{b}} \mathrm{N}=$ near and $\mathrm{F}=$ far side of row in a distance category.

${ }^{\mathrm{c}}$ Predicted distance at which $p$ declines to 0.10 , based on $a^{\prime}$ and $b^{\prime}$. The $d_{10}$ values were calculated using more decimal places for $a^{\prime}$ and $b^{\prime}$ than shown in the table; thus, exact values of $d_{10}$ are not obtained from the given $a^{\prime}$ and $b^{\prime}$ values.

${ }^{\mathrm{d}}$ Highest disease incidence was less than 0.10 , thus, $d_{10}$ cannot be calculated. 
ly lower mean incidence in treatment 1 than in the higher densities (Fig. 4).

For the first assessment time, the only significant interaction was for $T_{i}$ and $S_{j}(P \leq 0.01)$, indicating that the height of the gradient, but not the steepness, depended on the specific combination of density treatment and row side. For the second time, no interactions were significant (Table 1). Thus, for both times, estimated $b^{\prime}$ was the same for all treatments and row sides (Table 2), and $a^{\prime}$ depended on treatment and row side. Because there was no $T_{i} \times S_{j}$ interaction for assessment time 2, the difference in $a^{\prime}$ between the near and far row sides was the same for each density treatment (approximately 1.2 in logit scale) at this assessment time.

At the third assessment time, which had low mean disease incidence, the $T_{i}$ and $S_{j}$ interaction as well as the three-way interaction were significant (Table 1). This resulted in estimates of $a^{\prime}$ and $b^{\prime}$ being different for each combination of density treatment and row side (Table 2). Nevertheless, $a^{\prime}$ was lower for the far row side compared with the near side. At the last assessment time, there was one significant $(P \leq 0.01)$ interaction, $T_{i} \times d\left[(b T)_{i} d\right]$, indicating different estimates of $b^{\prime}$ for each density treatment (i.e., $b^{\prime}=b-$ $[b T]_{i}$ ), but not row side (Table 2 ).

Estimates of $d_{10}$, based on $a^{\prime}$ and $b^{\prime}$, were always higher for the near row side than the far side (Table 2). For instance, $d_{10}$ equaled
131 and $106 \mathrm{~cm}$ for the near and far sides, respectively, of the high plant density treatment (treatment 1) at the first assessment time. Generally, $d_{10}$ increased with decreasing plant density, although the largest values were found in treatment 3 at the last two assessments (e.g., $d_{10}=245 \mathrm{~cm}$ for treatment 3 at assessment time 4).

Diseased fruit and total fruit. As expected from fit of equation 2 to the data for each year, there was a highly significant $(P \leq 0.01)$ effect of number of fruit per plot ( $N$; fruit density) on disease incidence (Fig. 5B). Equation 3 provided an acceptable fit to the data for each year, although there was considerable variability, since the experimental factors (treatments, etc.) were not considered directly in this analysis. Disease incidence declined with increasing $N$, and the greatest change in $y$ with increasing $N$ was at low $N$.

There was also a significant $(P \leq 0.01)$ relationship between total number of diseased fruit per plot and $N$ (Fig. 5A), and equation 4 provided an acceptable fit to the data. Number of diseased fruit increased with $N$, although the greatest change was at low $N$. For over three-quarters of the range of $N$, there was little change in diseased fruit with increasing fruit density. Because experimental factors were not considered (as with equation 3), there was considerable variation around the curves.

Rain attenuation. In 1992, plant density treatment had a significant effect $(P \leq 0.01)$ on the (transformed) proportion of inci-
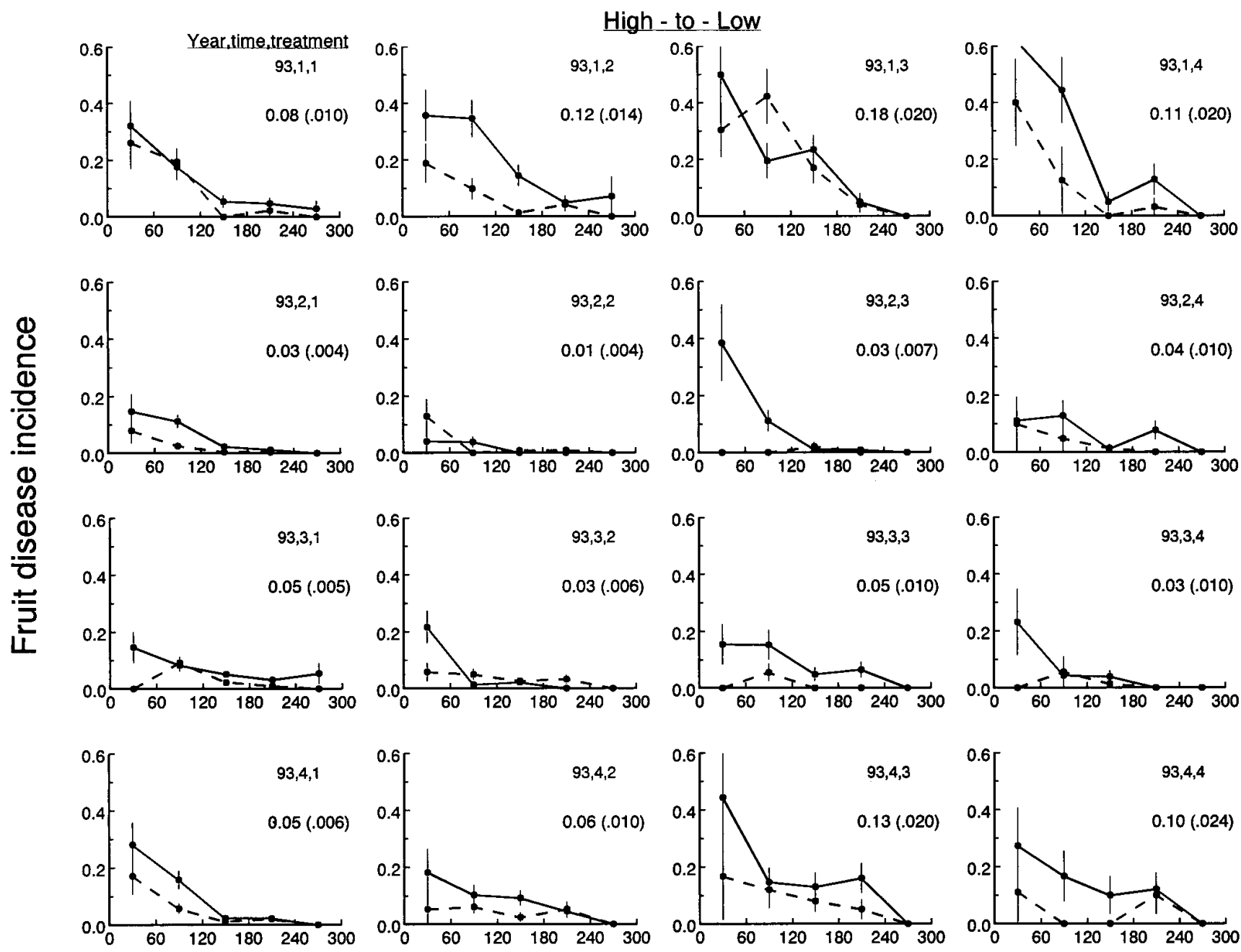

Distance $(\mathrm{cm})$

Fig. 4. Mean proportion of fruit visibly infected by Colletotrichum acutatum ( \pm standard errors) in relation to distance from point source of infected fruit in strawberry plots of four different plant densities (1 [high] to 4 [low], left to right across figure) at each of four assessment times (top to bottom of figure) in 1993. Lines within each subplot are for the near (solid) and far (dashed) side of rows relative to the initial inoculum source. Insert numbers are the treatment means (standard errors in parentheses) across all distances and row sides. For treatment 4 at the first time and near row side, mean disease incidence is 0.63 (cut off because of the common scale for all plots). 
dent rainfall that penetrated the row canopy (Fig. 6). Both the linear and nonlinear components were significant $(P \leq 0.01)$, reflecting the large increase in the proportion from treatment 3 to treatment 4 (lowest plant density) (Fig. 6). Rain episode $\left(E_{k}\right.$; i.e., time) also had a significant effect $(P \leq 0.01)$ on the proportion (data not shown). Both the linear and nonlinear components of time were significant $(P \leq 0.05)$, indicating that the proportion of rain intercepted depended on the individual rain episode, although the proportion generally declined over time (data not shown).

In 1993, density treatment also had a significant effect $(P \leq$ 0.01 ) on (transformed) proportion of rain penetrating the row canopy. There was an increase in the proportion with decreasing plant density (Fig. 6), and the linear component was significant $(P \leq$ $0.01)$, but the nonlinear component was not $(P>0.15)$. Rain episode (i.e., time) was not significant $(P>0.10)$.

Infection, postdeposition. In the second and third tests, plant density treatment did not have a significant effect $(P>0.05)$ on disease incidence of fruit that had been inoculated in the laboratory and placed in the row canopies, based on a GLM analysis. Means across all treatments were 0.21 (standard error $[\mathrm{SE}]=0.036$ ) and $0.11(\mathrm{SE}=0.032)$ for tests 2 and 3 , respectively. For the first test, incidence was significantly affected $(P \leq 0.05)$, and mean proportions of fruit infected for treatments 1 through 4 were 0.28 (SE $=0.087), 0.19(\mathrm{SE}=0.086), 0.39(\mathrm{SE}=0.062)$, and $0.56(\mathrm{SE}=$ $0.131)$, respectively. There were significant linear and nonlinear
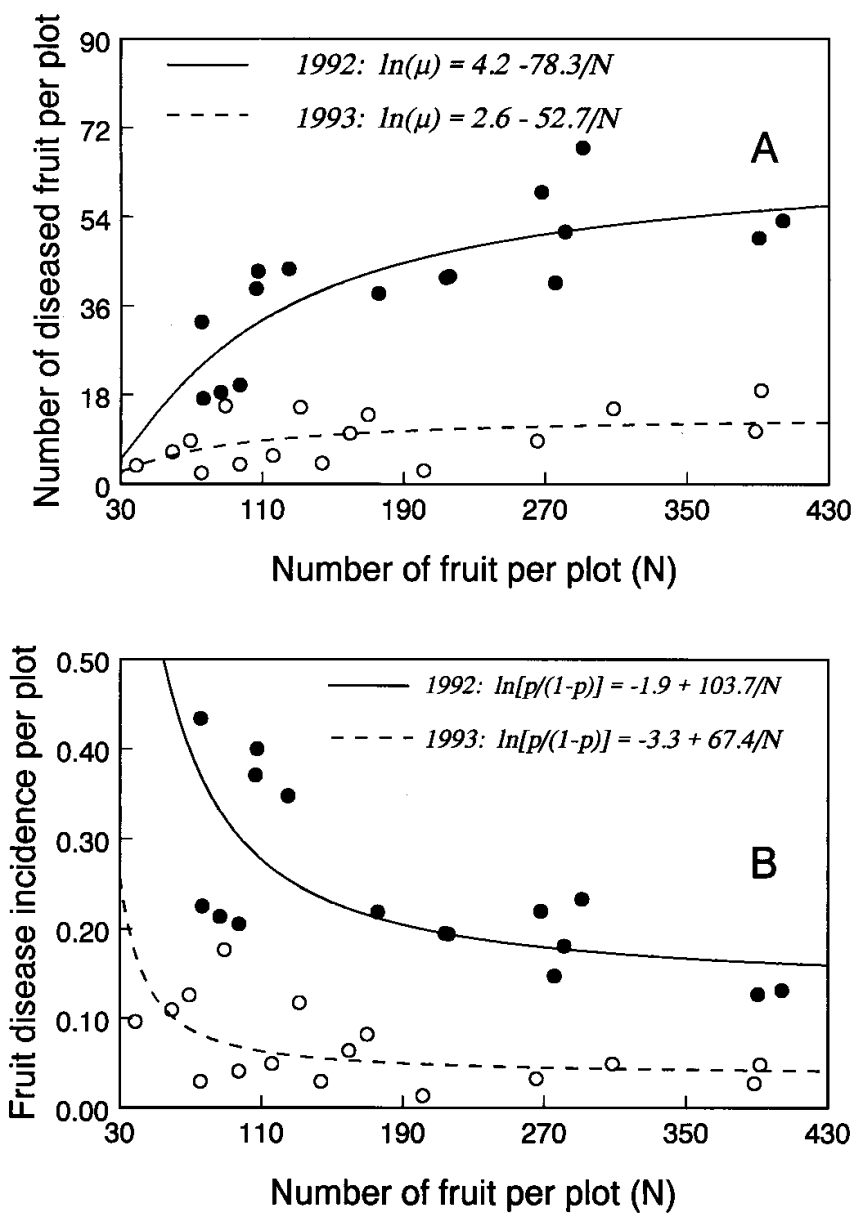

Fig. 5. Relationship between A, absolute numbers of diseased fruit per plot (totaled across all distances and row sides) in relation to total number of fruit per plot $(N)$; and $\mathbf{B}$, mean proportion of diseased fruit per plot (incidence) in relation to $N$, in 1992 and 1993 . Generalized linear models using a $\mathbf{A}, \log$ (equation 4) or $\mathbf{B}$, logit (equation 3 ) link function (with $\mu$ representing expected number of diseased fruit, and $p$ representing probability of being diseased) were fitted to the data. The deviance values were A, 28.8 (1992) and 37.3 (1993); and B, 52.5 (1992) and 42.1 (1993). changes $(P \leq 0.05)$ in the proportion with decreasing plant density. The mean proportion of fruit infected of those exposed to ambient conditions outside the plant canopies was $0.66(\mathrm{SE}=0.136)$.

\section{DISCUSSION}

Spread of anthracnose fruit rot was found in strawberry plots in each of 2 years by the determination of disease gradients in relation to distance from introduced point sources of $C$. acutatum inoculum. Disease spread was strongly influenced by the canopy, as evidenced by the significant effect of canopy row side (relative to the inoculum source) and plant density treatment on the height and steepness of the disease gradients. The near side overall had higher disease incidence than the far row side, and there was generally a negative, but nonlinear, relation between plant density and mean disease incidence. Rain attenuation also was directly related to plants per meter of row, but not necessarily in a linear manner. Although there were some differences between years in the complexity of the relationships between disease responses and row side or density treatment (reflected by the presence or absence of significant interactions), the results were in qualitative agreement.

We previously showed, using a rain simulator, that plant density strongly affected splash dispersal $(4,43)$ of $C$. acutatum. Other work also shows that the plant canopy can affect aspects of splash dispersal $(16,28)$. In Boudreau and Madden (4), total number of spores deposited in samplers increased as plant density decreased from 100 to $50 \%$ of the maximum density tested. Number of deposited spores then decreased or remained constant as plant density was further decreased to one lower density. Results from the field study found here are consistent with the rain simulation experiment. That is, there was a clear nonlinear relationship between disease response (mean $y, a^{\prime}, b^{\prime}$, and $d_{10}$ ) and plant density. In 1992, the mean disease incidence was low and similar for the higher two plant density treatments, and high and similar for the lower two densities. In 1993, mean disease incidence was low at the highest density (treatment 1), and reached its maximum at the next to the lowest density (treatment 3 ). For certain times, $d_{10}$ reached its largest value at this same plant density (treatment 3) (Table 2).

Unlike the rain simulation studies (4), our field investigation assessed disease development and not just spore dispersal. Nevertheless, we believe that differences in dispersal are responsible for most of the effects seen here. Postdeposition infection of fruit (for fruit inoculated in the laboratory and placed within the canopies) was affected by plant density treatment in only one of three tests in a single year of evaluation. In the test with the significant result,

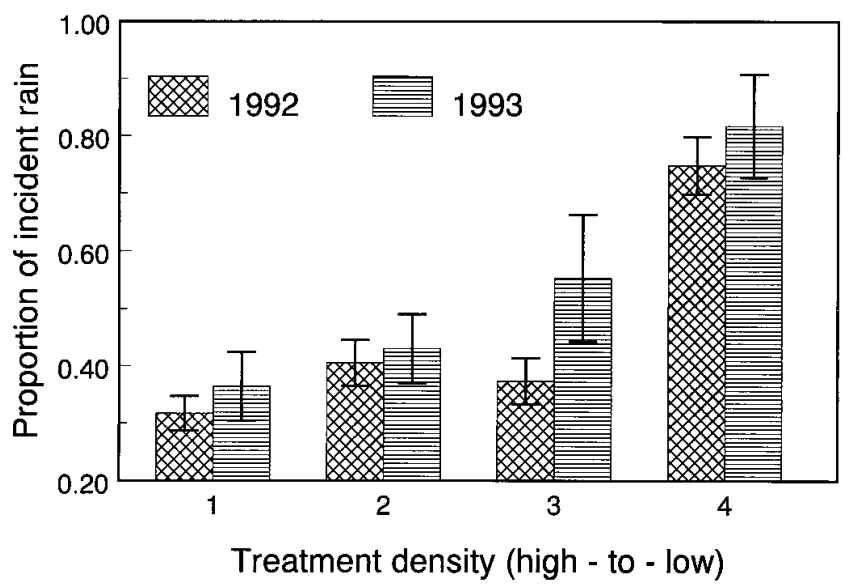

Fig. 6. Mean proportion of incident rain ( \pm standard errors) penetrating strawberry canopies of four densities (1 [high] to 4 [low]) in 1992 and 1993. Rain $\left(\mathrm{ml} \mathrm{cm}^{-2}\right)$ within the canopy was divided by rain $\left(\mathrm{ml} \mathrm{cm}^{-2}\right)$ over an open area to obtain proportions of the incident. Values are averages over rain episodes and replications. 
postdeposition infection level was only roughly related to mean $y$ from the disease gradient study. For instance, there was generally no difference in mean $y$ between the lowest two plant densities in 1992 (Fig. 2; treatments 3 and 4), but the proportion of diseased fruit that had been inoculated in the laboratory and placed within the canopies differed significantly by 0.17 between these two densities (0.39 versus 0.56$)$. Moreover, latent period and time to symptom appearance varied only by approximately 2 days from 18 to $22^{\circ} \mathrm{C}(26)$, suggesting that the minor temperature differences among the four canopies would have little effect on fruit colonization. As mentioned in the introduction, three interacting mechanisms were previously postulated to explain the complicated and nonlinear effects of density on dispersal (4). This study was not designed to test these mechanisms, but the results do not indicate any reason to reject them. In particular, based on the observed disease gradients, it seems likely that increasing plant density decreased the resplash of spore-carrying splash droplets across the plots, reducing the probability of a spore being deposited on a susceptible fruit. The complexity of the previously found relationship (4) was confirmed here as well. Dispersal in relation to rain attenuation (Fig. 6) is a case in point. In 1993, there was a linear increase in the proportion of rain penetrating the canopy with decreasing plant density, but the highest dispersal (i.e., highest mean y) often was found for the next to the lowest density (Fig. 4). Moreover, a low proportion of rain penetrated the canopy of treatment 3 compared with treatment 4 in 1992, but there typically was little difference in mean disease incidence $(y)$ between these two treatments (Fig. 2). Rain penetration is assumed to be related, in part, to splash droplet transport through the canopy, although other work shows that there is a nonlinear relation between horizontal transport of water through the canopy and plant density (42).

The GLM $(11,12)$ was found to be an acceptable way to represent disease spread (Table 1). The model realistically accounted for the statistical distribution of $y$ (11) and permitted the testing of plant density, distance, and row-side effects on $y$. The logit link function was used based on statistical theory (i.e., it produces a linear scale and is the so-called canonical link for the binomial distribution [11,23]) and our desire for the statistical model to reduce to the previously developed logistic disease spread model for a single plot $(8,25)$. Although distance from the inoculum source and row side cannot be randomized, by definition, their large deviances (Table 1) make it clear that both terms strongly affected disease incidence. Based on the GLM with only significant terms, plant density treatment and row-side effects could be quantified using the calculated $a^{\prime}$ and $b^{\prime}$, or $d_{10}$ for a combined result. The nonlinear relation between density and $y$ was directly assessed using an orthogonal decomposition of the $T_{i}$ (or interaction involving $T_{i}$ ). Furthermore, the interaction of $T_{i}$ and $S_{j}$ showed that, as expected, the magnitude of row-side effects depended on plant density. The most obvious manifestation of row side was seen by the large difference in $a^{\prime}$ between the near and far sides (Table 2). Depending on the assessment time and year, the difference was either constant (when there were no interactions) or dependent on treatment. Moreover, the row-side effect was so strong that mean $y$ at 90 or $150 \mathrm{~cm}$ from the inoculum source on the near side of rows was often higher than mean $y$ at $30 \mathrm{~cm}$ from the source on the far side (Figs. 2 and 4). Row side either did not affect gradient steepness, measured by $b^{\prime}$ (three of four assessment times in 1993), or steepness was reduced from the near to the far side. In either case, $d_{10}$ was almost always larger for the near than the far side.

Decreasing plant density sometimes resulted in decreasing $a^{\prime}$ (i.e., lower disease incidence next to the inoculum source), even though mean incidence increased from the highest to lowest plant density (e.g., assessment time 1 in 1992). However, $b^{\prime}$ also declined (i.e., became closer to zero) with decreasing plant density for some assessment times when $b^{\prime}$ was not constant, resulting (in part) in increasing $d_{10}$ with decreasing plant density. One implication of this combined result may be that $a^{\prime}$ is lower with decreased plant density because spores are traveling greater distances (i.e., smaller $b^{\prime}$ ) and are less restricted to infecting the fruit immediately adjacent to the source. However, full interpretation of rowside and density effects on $b^{\prime}$ requires an appraisal of the meaning of the parameter. Equation 1 is an expansion of the simple exponential model, $p=p_{0} \exp \left(-b^{\prime} d\right)$, and corrects for the upper limit to disease incidence (maximum $p$ [or $y$ ] of 1) $(8,25)$. If the dependent variable of the exponential model is number of spores (e.g., $p$ representing spores per unit area [8], not probability of a fruit being diseased), then $b^{-1}$ (centimeters) is the mean flight distance and a measure of the spatial scale of dispersal (15). Furthermore, at a distance of $d=b^{\prime-1}, p$ always equals $37 \%$ of the predicted value of $p$ at $d=0$ (i.e., $p / p_{0}=1 / \mathrm{e} \approx 0.37$ ) for the exponential model. The situation is more complicated for the logistic model (equation 1); $p / p_{0}$ at $d=b^{-1}$ depends on $a^{\prime}$ (or, equivalently, $p_{0}$ ). At small $a^{\prime}$ (say, $a^{\prime} \approx-2\left[p_{0} \approx 0.12\right]$ ), $p / p_{0}$ is 0.39 (about the same as the exponential); $p / p_{0}$ is 0.54 when $a^{\prime}=0\left(p_{0}=0.5\right), 0.68$ when $a^{\prime}=1\left(p_{0}=0.73\right)$, and 0.83 when $a^{\prime}=2\left(p_{0}=0.88\right)$. In other words, for high values of disease incidence near the source (i.e., large $a^{\prime}$ ), incidence is still very high at a distance equal to $b^{\prime-1}$. Thus, $b^{\prime}$ generally should not be used alone to summarize spread. Comparison of $b^{\prime}$ values depends on the magnitude of $a^{\prime}$ (or, equivalently, $p_{0}$ ).

Although there are arguments in favor of a positive relationship between plant density and disease intensity $(6,7,20,21,39)$, empirical results are inconclusive $(2,5,9,13,20,24,27,38,40)$. In some natural systems with a positive correlation (40), there is evidence that the correlation could be due to resource limitations for the host and pathogen (i.e., environmental interaction), rather than a direct effect of the host density on the pathogen dynamics. Theory from animal systems (1) indicates that the rate of increase in absolute numbers of diseased individuals will increase with either (i) the absolute density of diseased (and healthy) individuals, or (ii) relative density of diseased (and healthy) individuals (e.g., proportion diseased), depending on the transmission mechanism. However, disease incidence or severity data (recorded as proportions) are standard in most botanical epidemiological studies (8), complicating interpretation, although proportion data have been used to support a positive correlation (6) between plant density and disease. In our study, the number of diseased fruit generally increased with increasing number of fruit per plot (Fig. 5A), as predicted (1). However, the general qualitative trend is less informative than the functional relationship. For instance, if the number of fruit per plot doubled (perhaps due to doubling the plants per plot), then one would expect that number of diseased fruit also would increase. However, the magnitude of the increase may be considerably less than the increase in total fruit, due to the sheltering of fruit by other fruit and plants, barrier effects on splash droplet movement as discussed here and elsewhere (4), and a dilution of spore density per fruit. Thus, increases in diseased fruit at a magnitude less than the increase in total fruit, or a declining rate of increase in diseased fruit with increasing total fruit, are indications of a negative relationship between plant (or fruit) density and the probability of a fruit being diseased. As shown in Figure 5A, there was very little increase in total diseased fruit with increasing $N$ at values of $N$ above 100 . This is confirmed by the acceptable fit of equation 4 and negative estimated $\beta$, which indicates a declining rate of increase in diseased fruit with increasing $N$. There was, thus, a declining disease incidence (y) with increasing $N$ (Fig. 5B), as expected from the general trend of declining mean $y$ with increasing plant density (Figs. 2 and 4 ) and the results of the full GLM (equation 2) shown in Tables 1 and 2.

For the epidemiological theory of Anderson and May (1) to be fully relevant, there would need to be sufficient generations (within a season or over many years, depending on the pathosystem) for the disease to approach equilibria or asymptotic intensities. That is, there would need to be time for several generations of plant-toplant (or fruit-to-fruit) spread. Many economically important di- 
seases, however, are monocyclic, at least within a single year (18), and it is not clear from the limited empirical evidence reported to date how plant density would affect these situations (35). Obviously, increasing density will increase the probability of a propagule coming in contact with a plant unit immediately adjacent to the source of the propagules; however, at greater distances, the increased density will also increase the barriers (per unit of area) between propagules and plant units. Even immediately adjacent to the source, density effects are not certain. That is, as discussed in the preceding paragraph, increasing density may result in more units becoming infected, but since the total number of units is increasing, the proportion diseased could be constant or decrease. There is clear evidence from some systems that dispersal of spores or other microscopic particles, such as pollen, declines with increasing plant density $(13,33)$. Interestingly, some recent work showing no relation between plant density and disease in natural systems $(27,38)$ deals with heteroecious rusts on the host with no secondary spread. Thus, the effect seen would likely be due to altered dispersal with increasing density (as found by us) or altered environmental conditions. With day length-sensitive strawberry cultivars (i.e., one generation of fruit per season) and an approximately 6- to 9-day latent period for anthracnose (26), there is time for only a small number of generations, and the disease under investigation here may behave more like a monocyclic than polycyclic disease, especially when ripe fruit are harvested.

It is now well established that surface topography (e.g., surface random roughness [43]) can have a dramatic effect on rain splash dispersal of fungal plant pathogens $(28,29)$. Increasing roughness can often negate the effects of increasing rain amount or intensity on spore dispersal. For instance, a straw mulch, typically used for perennial strawberry production (19), drastically reduces disease spread in the field $(30,37)$. Increasing plant density in the current study had a qualitatively similar effect as increasing roughness $(28,29,42,43)$, although the magnitude of the effect was less for plant density manipulation. Although changing density alone, within the production constraints of a particular crop, may not be sufficient to manage diseases such as anthracnose, alteration of density could be used in conjunction with other practices to improve disease control. Additionally, density effects have a direct bearing on use of cultivar mixtures for controlling anthracnose and other diseases (10).

\section{ACKNOWLEDGMENTS}

Salaries and support provided by state and federal funds (especially USDA NRI grants 91-37303-5857 and 95-37303-1788) appropriated to the Ohio Agricultural Research and Development Center, The Ohio State University, Wooster. Journal article 08-97. We thank L. L. Wilson and W. King for technical assistance.

\section{LITERATURE CITED}

1. Anderson, R. M., and May, R. M. 1979. Population biology of infectious diseases: Part I. Nature 280:361-367.

2. Augspurger, C. K. 1988. Impact of pathogens on natural plant populations. Pages 413-433 in: Plant Population Ecology. A. J. Davy, M. J. Hutchings, and A. R. Watson, eds. Blackwell Scientific Publications Ltd., Oxford.

3. Boudreau, M. A., and Madden, L. V. 1994. An automated device for characterizing rainfall. (Abstr.) Phytopathology 84:1126.

4. Boudreau, M. A., and Madden, L. V. 1995. Effect of strawberry density on dispersal of Colletotrichum acutatum by simulated rain. Phytopathology 85:934-941.

5. Burdon, J. J., and Chilvers, G. A. 1975. Epidemiology of damping-off disease (Pythium irregulare) in relation to density of Lepidium sativum seedlings. Ann. Appl. Biol. 81:135-143.

6. Burdon, J. J., and Chilvers, G. A. 1982. Host density as a factor in plant disease ecology. Annu. Rev. Phytopathol. 20:143-166.

7. Burdon, J. J., Wennstrom, A., Ericson, L., Muller, W. J., and Morton, R. 1992. Density-dependent mortality in Pinus sylvestris caused by the snow blight pathogen Phacidium infestans. Oecologia 90:74-79.
8. Campbell, C. L., and Madden, L. V. 1990. Introduction to Plant Disease Epidemiology. John Wiley \& Sons, New York.

9. Carlsson, U., Elmqvist, T., Wennström, A., and Ericson, L. 1990. Infection by pathogens and population age of host plants. J. Ecol. 78:1094-1105.

10. Chakraborty, S., Pettitt, A. N., Choy, S. L., and Boland, R. M. 1995. Spatial dependence in anthracnose development in mixtures of Stylosanthes scabra. J. Phytopathol. 143:693-699.

11. Collett, D. 1991. Modelling Binary Data. Chapman \& Hall, London.

12. Crawley, M. J. 1993. GLIM for Ecologists. Blackwell Scientific, London.

13. de Nazareno, N., Madden, L. V., and Lipps, P. E. 1993. Characterization of gray leaf spot epidemics of maize. Z. Pflanzenkr. Pflanzenschutz 100: 410-425.

14. Dobson, A., and Crawley, M. 1994. Pathogens and the structure of plant communities. Trends Ecol. Evol. 9:393-398.

15. Ferrandino, F. J. 1996. Length scale of disease spread: Fact or artifact of experimental geometry. Phytopathology 86:806-811.

16. Fitt, B. D. L., Inman, A. J., Lacey, M. E., and McCartney, H. A. 1992. Splash dispersal of spores of Pseudocercosporella capsellae (white leaf spot) from oilseed rape leaves of different inclination, flexibility and age. Z. Pflanzenkr. Pflanzenschutz 99:1-15.

17. Fitt, B. D. L., McCartney, H. A., and Walklate, P. J. 1989. The role of rain in dispersal of pathogen inoculum. Annu. Rev. Phytopathol. 27:241-270.

18. Fry, W. E. 1982. Principles of Plant Disease Management. Academic Press, Inc., New York.

19. Funt, R. C. 1994. Ohio Strawberry Production, Management, and Marketing Manual. Ohio State University Extension, Columbus.

20. Garciaguzman, G., Burdon, J. J., Ash, J. E., and Cunningham, R. B. 1996. Regional and local patterns in the spatial distribution of the flower-infecting smut fungus Sporisorium amphilophis in natural populations of its host Bothriochloa macra. New Phytol. 132:459-469.

21. Gilbert, G. S., Hubbell, S. P., and Foster, R. B. 1994. Density and distance-to-adult effects of a canker disease of tree in a moist tropical forest. Oecologia 98:100-108.

22. Healy, M. J. R. 1988. GLIM: An Introduction. Clarendon Press, Oxford.

23. Hughes, G., and Madden, L. V. 1995. Some methods allowing for aggregated patterns of disease incidence in the analysis of data from designed experiments. Plant Pathol. 44:927-943.

24. Huisman, O. C., and Grimes, D. W. 1989. Cultural practices: The effect of plant density and irrigation regimes on Verticillium wilt of cotton. Pages 537-541 in: Vascular Wilt Diseases of Plants: Basic Studies and Control. E. C. Tjamos and C. H. Beckman, eds. Springer-Verlag, New York.

25. Jeger, M. J. 1983. Analysing epidemics in time and space. Plant Pathol. 32:5-11.

26. King. W. T., Madden, L. V., Ellis, M. A., and Wilson, L. L. 1997. Effects of temperature on sporulation and latent period of Colletotrichum spp. infecting strawberry fruit. Plant Dis. 81:77-84.

27. Lively, C. M., Johnson, S. G., Delph, L. F., and Clay, K. 1995. Thinning reduces the effect of rust infection on jewelweed (Impatiens capensis). Ecology 76:1859-1862.

28. Madden, L. V. 1992. Rainfall and the dispersal of fungal spores. Adv. Plant Pathol. 8:39-79.

29. Madden, L. V., and Ellis, M. A. 1990. Effect of ground cover on splash dispersal of Phytophthora cactorum from strawberry fruits. J. Phytopathol. 129:170-174.

30. Madden, L. V., Wilson, L. L., and Ellis, M. A. 1993. Field spread of anthracnose fruit rot of strawberry in relation to ground cover and ambient weather conditions. Plant Dis. 77:861-866.

31. Madden, L. V., Wilson, L. L., Yang, X., and Ellis, M. A. 1992. Splash dispersal of Colletotrichum acutatum and Phytophthora cactorum by short-duration simulated rains. Plant Pathol. 41:427-436.

32. Milliken, G. A., and Johnson, D. E. 1984. Analysis of Messy Data, Volume 1: Designed Experiments. Van Nostrand Reinhold, New York.

33. Morris, W. F. 1993. Predicting the consequences of plant spacing and biased movement for pollen dispersal by honey bees. Ecology 74:493-500.

34. Power, A. G. 1989. Influence of plant spacing and nitrogen fertilization in maize on Dalbulus maidis (Homoptera: Cicadellidae), vector of corn stunt. Environ. Entomol. 18:494-498.

35. Power, A. G. 1990. Cropping systems, insect movement, and the spread of insect-transmitted diseases in crops. Pages 47-69 in: Agroecology: Researching the Ecological Basis for Sustainable Agriculture. S. R. Gliessman, ed. Springer-Verlag, New York.

36. Power, A. G. 1992. Host plant dispersion, leafhopper movement, and disease transmission. Ecol. Entomol. 17:63-68.

37. Reynolds, K. M., Madden, L. V., and Ellis, M. A. 1988. Spatio-temporal analysis of epidemic development of leather rot of strawberry. Phytopathology 78:246-252.

38. Roy, B. A. 1993. Patterns of rust infection as a function of host genetic diversity and host density in natural populations of the apomictic crucifer, Arabis holboellii. Evolution 47:111-124.

39. Waggoner, P. E. 1986. Progress curves of foliar diseases: Their interpre- 
tation and use. Pages 3-37 in: Plant Disease Management, Vol. 1. K. J. Leonard and W. E. Fry, eds. Macmillan Publishing Co., New York.

40. Wennström, A., Ericson, L., and Elveland, J. 1995. The dynamics of the plant Lactuca sibirica and the frequency of its rust Puccinia minussensis in river valleys in northern Sweden. Oikos 72:288-292.

41. Wilson, L. L., Madden, L. V., and Ellis, M. A. 1990. Influence of temperature and wetness duration on infection of immature and mature strawberry fruit by Colletotrichum acutatum. Phytopathology 80:111-116.
42. Yang, X., and Madden, L. V. 1993. Effects of ground cover, rain intensity, and strawberry plants on splash of simulated raindrops. Agric. For. Meteorol. 65:1-20.

43. Yang, X., Madden, L. V., Wilson, L. L., and Ellis, M. A. 1990. Effects of surface topography and rain intensity on splash dispersal of Colletotrichum acutatum. Phytopathology 80:1115-1120.

44. Yang, X., Wilson, L. L., Madden, L. V., and Ellis, M. A. 1990. Rain splash dispersal of Colletotrichum acutatum from infected strawberry fruit. Phytopathology 80:590-595. 